\title{
Author Correction: Light triggers PILS-dependent reduction in nuclear auxin signalling for growth transition
}

Chloé Béziat, Elke Barbez, Mugurel I. Feraru, Doris Lucyshyn and Jürgen Kleine-Vehn

Correction to: Nature Plants https://doi.org/10.1038/nplants.2017.105, published online 17 July 2017.

In Fig. 2a of this Article originally published, the image indicating the 40-h WT condition was mistakenly a duplicate of the 60-h pils2 pils5 condition. The corrected Fig. 2 is shown below.

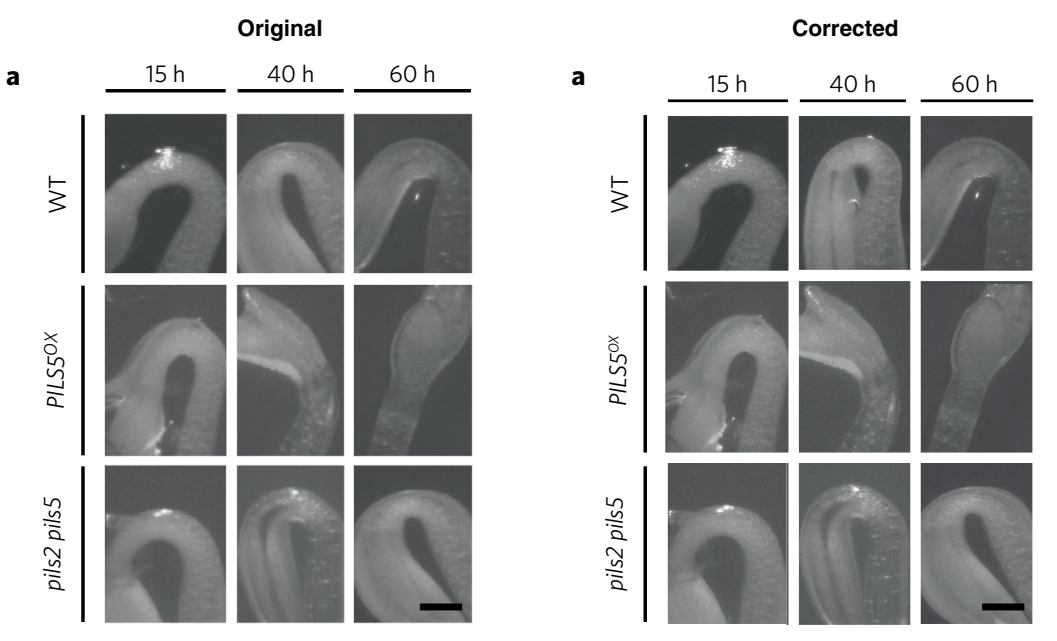

Fig. 2 | Corrected.

Published online: 4 May 2021

https://oi.org/10.1038/s41477-021-00924-y

๑ The Author(s), under exclusive licence to Springer Nature Limited 2021 